\title{
ANALYSIS AND DESIGN OF FLAT SLABS USING VARIOUS CODES
}

\author{
S.S.Patil ${ }^{1}$, Rupali Sigi ${ }^{2}$ \\ ${ }^{1}$ Head of Department, Civil Engineering Department, Walchand Institute of Technology, Maharashtra, India \\ ${ }^{2}$ Student, Civil Engineering Department, Walchand Institute of Technology, Maharashtra, India
}

\begin{abstract}
"Flat Slab" is better understood as the slab without beams resting directly on supports (like columns \& or walls). By virtue of that large Bending Moment \& Shear Forces are developed close to the columns. These stresses brings about the cracks in concrete \& may provoke the failure of slab, thus there is a need to provide a larger area at the top of column recognized as column head/ capital. The analysis of flat slab is executed by Direct Design Method (DDM) \& Equivalent Frame Method (EFM) as directed by different standard, however the Finite element analysis \& Equivalent frame analysis is carried out by using software SAFE (Slab Analysis by Finite element method and Equivalent frame method). The analysis \& design is performed by Equivalent Frame Method with staggered column \& without staggered column as prescribed in the different codes like IS 456-2000, ACI 318-08, BS 8110-1997, EC2 Part1 2004 are compared. In this process moments are distributed as column strip moments \& middle strip moments. The methodology for analysis \& design of slab is thoroughly explained in the paper. Equivalent frame analysis is also carried out for distribution of column strip moments \& middle strip moments by using software SAFE. Excel worksheets for analysis and design of flat slab using equivalent frame method for all standard codes are also prepared.
\end{abstract}

Keywords: Flat Slab, IS 456-2000, ACI 318-08, BS 8110-1997, EC2 Part I 2004 etc...

\section{INTRODUCTION}

Claud A. P. Turner was one of the early advocates of flat slab system known as "mushroom" system. C.A.P. Turner constructed flat slabs in U.S.A. in 1906 mainly using intuitive and conceptual ideas, which was start of this type of construction. Many slabs were load-tested between 1910- 20 in U.S.A. It was only in 1914 that Nicholas proposed a method of analysis of flat slabs based on simple statics. This method is used even today for the design of flat slabs and flat plates and is known as the direct design method.

Structural engineers commonly use the equivalent frame method with equivalent beams such as the one proposed by Jacob S. Grossman in practical engineering for the analysis of flat plate structures.

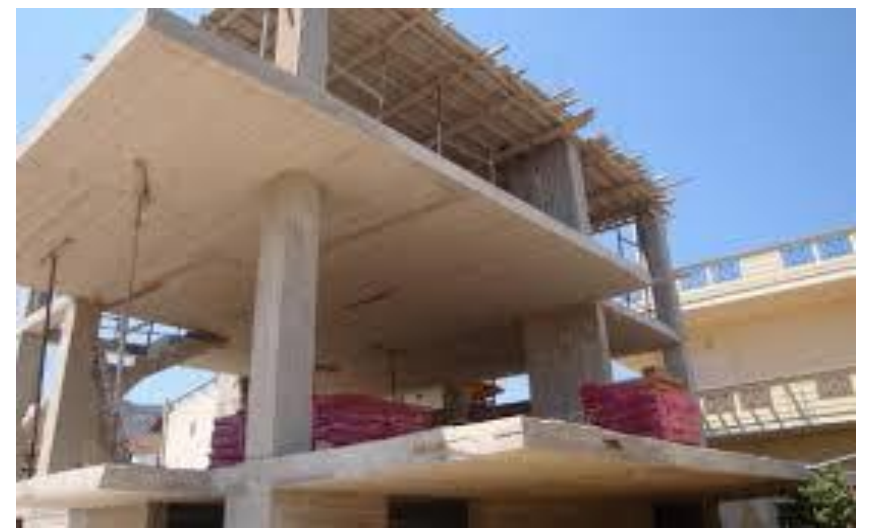

Architectural demands for better illumination, lesser fire resistance of sharp corners present in the form of beams \& increase in the formwork cost, optimum use of space leads to the new concept in the field of structural engineering as Reinforced concrete flat slabs.

Plan showing staggered interior columns.

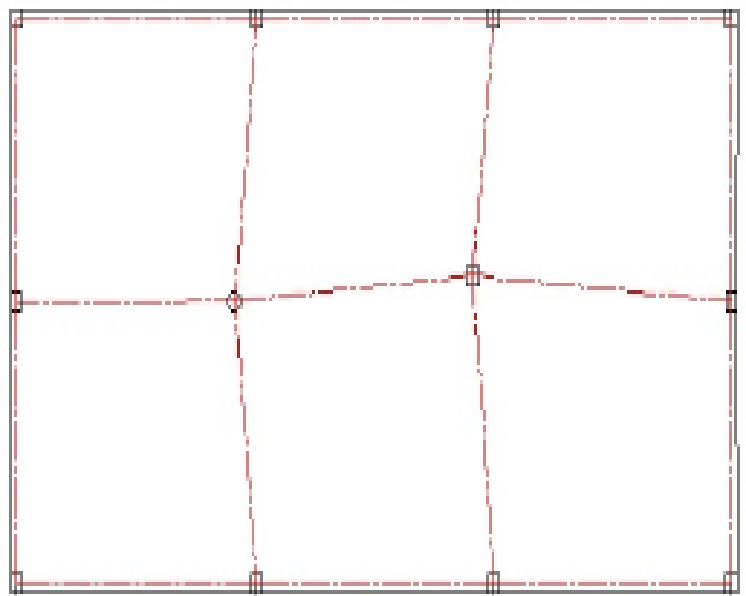

Fig: Components of Flat slab (panel)

Main components of flat slab are. [a] Panel. [b] Drop. [c] Column head. [d] Column strip. [e] Middle strip. 


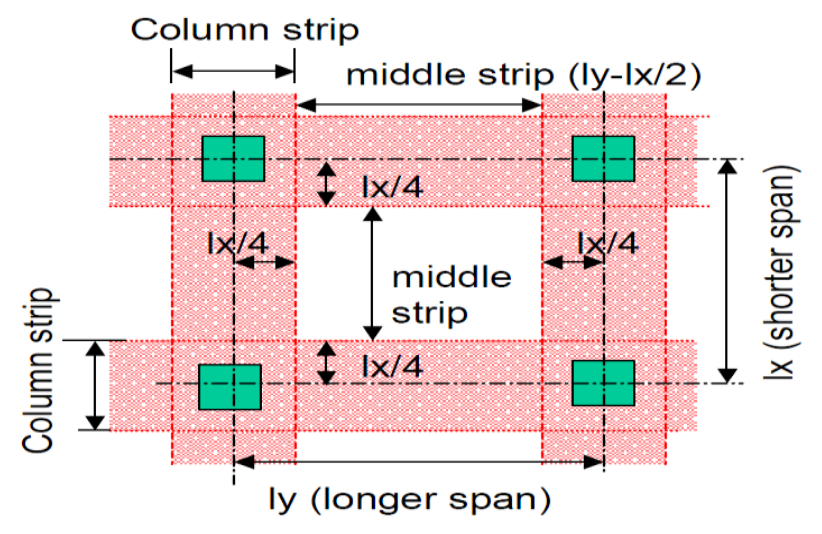

Fig: Components of Flat slab (Column strip, middle strip)

Behavior of flat slab and flat plates are identical to those of two way slab. Bands of slab in both directions along column lines are considered to act as beams. Such bands of slabs are referred as column strips which pass through the columns and middle strips, occur in the middle of two adjacent columns. The deflections are minimum at supports and maximum at mid spans. The deflected flat slab at the center of panel shall have saucer shape. Where $\delta \mathrm{x}$ and $\delta \mathrm{y}$ is the deflection at midspan in $\mathrm{X}$ and $\mathrm{Y}$ direction and $\mathrm{x}$ and ly is the span length in $\mathrm{X}$ and $\mathrm{Y}$ direction.

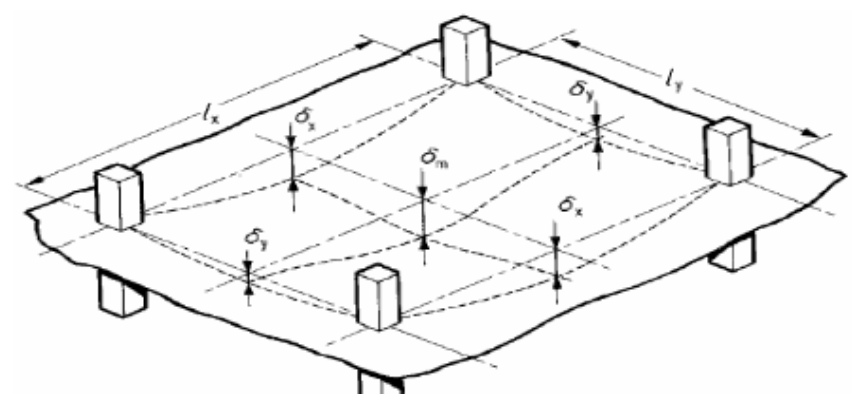

Fig: Deflection profile of Flat slab

\subsection{Objective}

A Reinforced Concrete flat slab floor is a significant advancement in the building technology. It has been observed that possible failure mode of the Reinforced concrete Flat slabs is punching that occurs in the vicinity of a column. The main objective of the study is to study method of analysis and design of flat slab with staggered column by IS 456-2000 [2], ACI 318-08 [3], BS 8110-1997 [4] \& EC2:Part1-2004 [5]. Each code has specified the fixed coefficients for lateral and transverse distribution of moments as per direct design method and equivalent frame method. The project is aimed to determine the effect of staggered column spacing and its combination of shapes such as circular, rectangular and square columns. Also check whether those moments are remain the same when we analyze the flat slab with use of software SAFE. Project is also aimed to prepare the Excel worksheet for analysis and design of the flat slab with staggered column by equivalent frame method.

\subsection{Scope of Work}

The project works is concerned with the Analysis and Design of Flat slab with and without staggered column and to prepare the worksheet for analysis and design of flat slabs. The scope of work will be as below.

- Analysis and design of flat slabs is to be carried out for staggered columns using Equivalent Frame Method with IS 456-2000, ACI 318-08, BS 8110-1997 \& EC2:Part1-2004.

- Analysis of flat slab with equivalent frame method using software SAFE.

- Preparation of excel worksheet analysis and design of flat slab with staggered column as per IS 456-2000, ACI 31808, BS 8110-1997 \& EC2:Part1-2004.

\section{METHODOLOGY}

Every code suggests any of the two methods as Direct Design Method and Equivalent Frame Method for gravity load analysis of flat slab. Design of Flat slab by Direct Design Method has some restrictions that (a) It should have minimum three spans in each directions. (b) It should not have staggered column orientation. Hence Equivalent Frame Method is adopted.

\subsection{Equivalent Frame Method}

In this method moments at each joint is calculated by Moment Distribution Method using the Fixed End Moment on each span. Using those moments calculate negative moments at both left $\&$ right support i.e. $\left(\mathrm{M}_{\mathrm{u}}^{-}\right) \&$ the maximum positive moments in the middle of span i.e. $\left(\mathrm{M}_{\mathrm{u}}^{+}\right)$.

All the Negative \& Positive moments are distributed in the column strips \& Middle strips respectively using equivalent codes.

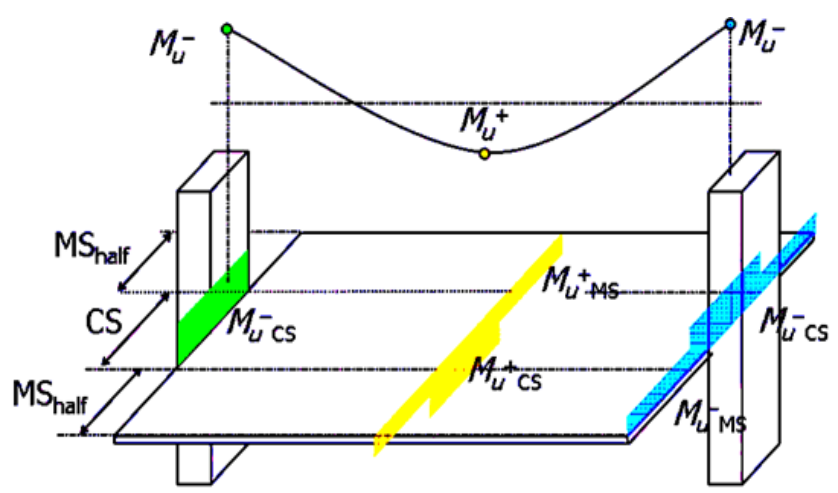

Fig: Distribution moment to the column strip and the moment strip 


\section{Example:}

IS 456-2000[2] Distribution of moments across panels for Exterior Slab

\begin{tabular}{|l|ll|l|l|}
\hline Sr. No. & Distributed moment & $\begin{array}{l}\text { Column strip Middle strip } \\
\text { moment \% }\end{array}$ & $\begin{array}{l}\text { Moment } \% \\
\text { mom }\end{array}$ \\
\hline A & Negative $\quad$ BM & at 100 & 0 \\
\hline B & Negative BM & at75 & 25 \\
\hline C & Positive BM at & 60 & 40 \\
\hline
\end{tabular}

IS 456-2000[2] Distribution of moments across panels for Interior Slab

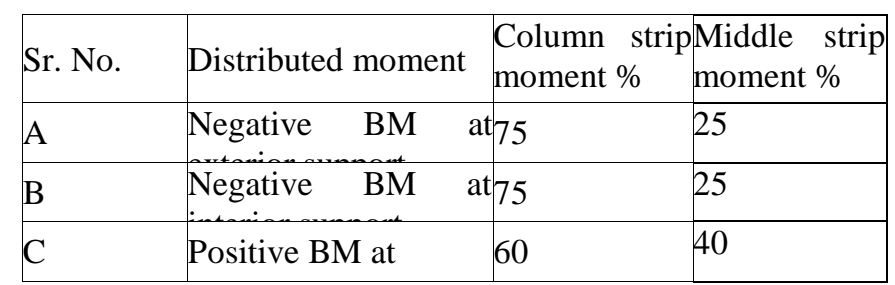

ACI 318[3] Distribution of moments across panels for Slab

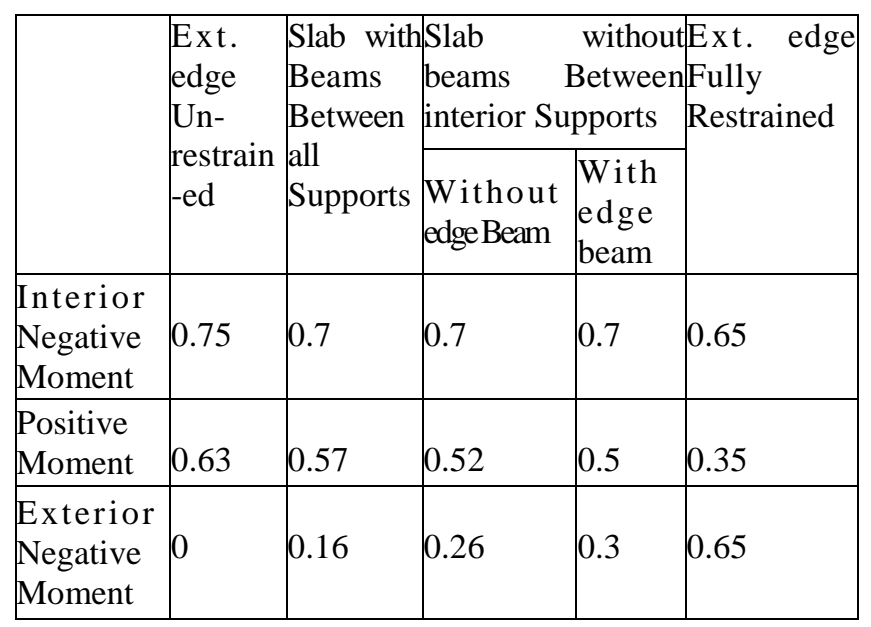

BS 8110-1997[4], EC2 [5] Distribution of moments across panels for Slab

\begin{tabular}{|l|l|l|}
\hline Design moment & column strip & Middle strip \\
\hline Negative & $75 \%$ & $25 \%$ \\
\hline Positive & $55 \%$ & $45 \%$ \\
\hline
\end{tabular}

The unbalanced slab moments at various supports are transmitted to respective columns. This unbalanced slab moment is shared by the column above \& below in proportion to their relative stiffness. These moments are transferred by punching shear \& flexure in the column. The punching shear produces cracks at the critical section close to the column faces as shown below,
Example:

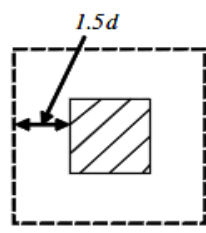

as BS \& EURO Code

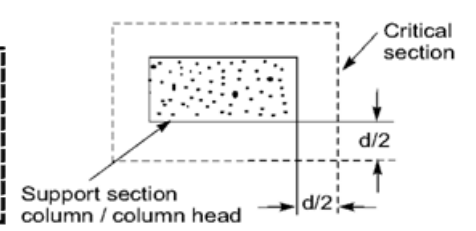

as IS 456 \& ACI code
Fig: Critical section for shear

The shear stress is calculated as explained in the respective codes of the countries. The permissible shear stress is also calculated same as Explained in respective country codes. The shear reinforcement should be provided if the actual shear stress found to be greater than permissible shear stress.

The distribution of moments calculated is shown in the table

\begin{tabular}{|l|l|l|l|l|}
\hline \multicolumn{5}{|l|}{ DISTRIBUTION OF MOMENTS RESULT } \\
\hline & \multicolumn{2}{l|}{ Exterior Slab } \\
\hline FRAME & & Mul- & Mu+ & Mur- \\
\hline \multirow{4}{*}{ F } & IS & A11 & B11 & C11 \\
\cline { 2 - 5 } & ACI & A21 & B21 & C21 \\
\cline { 2 - 5 } & BS & A31 & B 31 & C 31 \\
\cline { 2 - 5 } & EURO & A41 & B41 & C41 \\
\hline
\end{tabular}

Graph compared to the table can be created like,

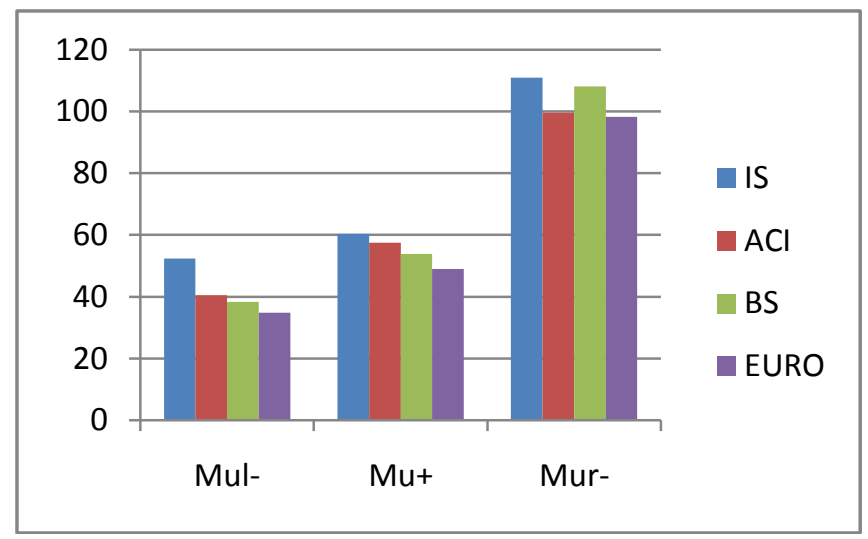

\begin{tabular}{|l|l|l|l|l|}
\hline \multicolumn{5}{|l|}{ DISTRIBUTION OF MOMENTS RESULT } \\
\hline & \multicolumn{4}{l|}{ Interior Slab } \\
\hline FRAME & & Mul- & Mu+ & Mur- \\
\hline \multirow{4}{*}{ F } & IS & A12 & B12 & C12 \\
\cline { 2 - 5 } & ACI & A22 & B22 & C22 \\
\cline { 2 - 5 } & BS & A32 & B32 & C32 \\
\cline { 2 - 5 } & EURO & A42 & B42 & C42 \\
\hline
\end{tabular}


Graph compared to the table can be created like,

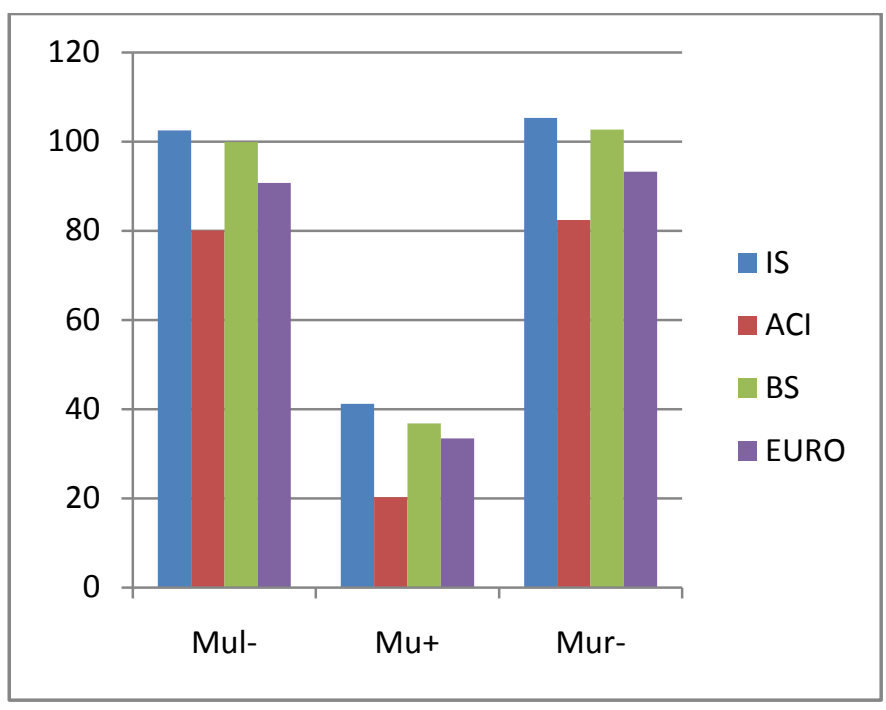

\section{Comparison}

The positive mid-span moment is increasing and negative moment is decreasing when we analyze the slab with Equivalent Frame Method.

The negative moment's section shall be designed to resist the larger of the two interior negative design moments for the span framing into common supports.

Negative \& Positive moments at exterior support is increases for IS 456-2000 as compared to (ACI 318-08, BS 8110-1997, EC2:Part1-2004) for Equivalent Frame Method.

In the Exterior support, the total design moments (Mo) are distributed as $100 \%$ in column strip and $0 \%$ in middle strip in both the case IS 456-2000 and ACI 318-08 \& the total design moments (Mo) are distributed as $75 \%$ in column strip and 25\% in middle strip in both the case BS 8110-1197 and EC2Part1-2004.

\begin{tabular}{|l|l|l|l|}
\hline \multicolumn{3}{|l|}{ PUNCHING SHEAR RESULTS } \\
\hline column & & punching ratio & Depth \\
\hline \multirow{4}{*}{ F } & IS & a1 & b1 \\
\cline { 2 - 4 } & ACI & a2 & b2 \\
\cline { 2 - 4 } & BS & a3 & b3 \\
\cline { 2 - 4 } & EURO & a4 & b4 \\
\hline
\end{tabular}

The graph of punching ratio to depth created shows

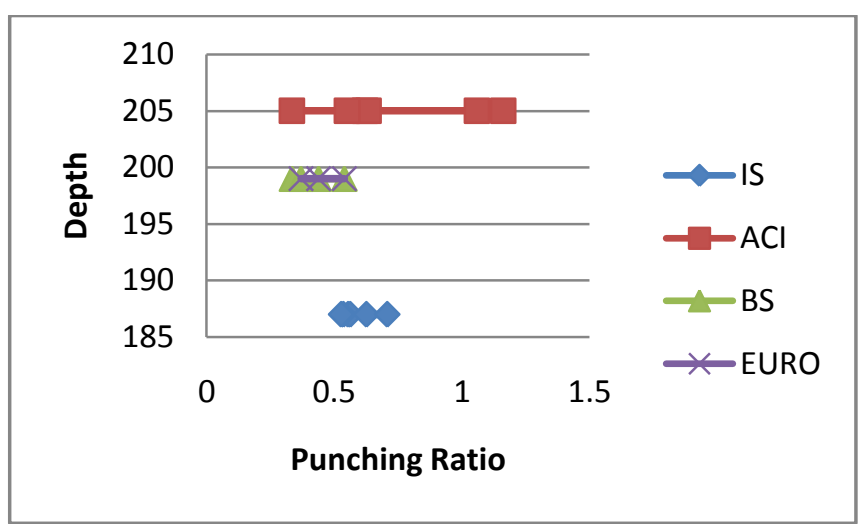

\section{CONCLUSIONS}

[1]. The positive mid-span moment is increasing and negative moment is decreasing when we analyze the slab with Equivalent Frame Method.

[2]. The negative moment's section shall be designed to resist the larger of the two interior negative design moments for the span framing into common supports.

[3]. Negative \& Positive moments at exterior support is increases for IS 456-2000 as compared to (ACI 318-08, BS 8110-1997, EC2:Part1-2004) for Equivalent Frame Method.

[4]. In the Exterior support, the total design moments (Mo) are distributed as $100 \%$ in column strip and $0 \%$ in middle strip in both the case IS 456-2000 and ACI 318-08 \& the total design moments (Mo) are distributed as $75 \%$ in column strip and $25 \%$ in middle strip in both the case BS 8110-1197 and EC2Part1-2004.

[5]. In flat slab (with \& without staggered column) in both cases the punching shear criteria is satisfy except Interior columns as per ACI 318-08 as compared to other code.

\section{ACKNOWLEDGEMENTS}

We sincerely acknowledge and express my deep sense of gratitude to Mr. S. A. Halkude (Principal Walchand Institute of Technology).

\section{REFERENCES}

[1]. P.C. Varghese "Advanced Reinforced Concrete Design", prentice hall of India limited, New Delhi, EEE (2002).

[2]. Bureau of Indian Standards, New Delhi, "IS 456:2000, Plain and Reinforced Concrete - Code of Practice", Fourth Revision, July (2000).

[3]. American Concrete Institute, "ACI 318-08, Building Code Requirements for Structural Concrete and Commentary", January (2008).

[4]. British Standard, "BS 8110-1:1997, Code of practice for design and construction”, March (1997). 
[5]. European Standard, "Euro code 2:Part1-2004, Design of concrete structures - Part 1-1: General 2rules and rules for buildings", December (2004).

[6]. M.Anitha, B.Q.Rahman and JJ.Vijay, "Analysis and Design of Flat Slabs Using Various Codes", International Institute of Information Technology, Hyderabad, April (2007).

\section{BIOGRAPHIES}

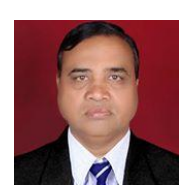

Prof. S. S. Patil, Head of Department, Civil Engineering, Walchand Institute of Technology

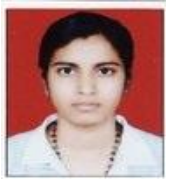

Rupali A. Sigi, Student: Masters of Engineering (civil), Walchand Institute of Technology 